\title{
O direito da parturiente ao acompanhante como instrumento de prevenção à violência obstétrica
}

The parturient's right to a companion as an instrument to prevent obstetric violence

El derecho del parturient a un compañero como instrumento para prevenir la violencia obstétrica

Natalie Maria de Oliveira de Almeida ${ }^{1,2}$ Edith Maria Barbosa Ramos ${ }^{3}$

\section{Resumo}

Objetivo: realizar uma revisão sistemática de estudos acerca da violência obstétrica, refletindo sobre o direito da parturiente ao acompanhante enquanto meio de prevenção da incolumidade de sua saúde física e psicológica. Metodologia: levantamento bibliográfico de artigos obtidos em diferentes bancos de dados e indexadores, publicados na íntegra em português e acessados de forma gratuita no período de agosto de 2019 a julho de 2020 . Foram selecionadas revistas científicas na área do Direito Sanitário e da Saúde Coletiva, com extratos A e B no Qualis/Capes. Utilizou-se, ainda, dados constantes em documentos oficiais disponibilizados nos sites do Ministério da Saúde brasileiro, da Fundação Perseu Abramo e da Organização Mundial de Saúde. Resultados: verificou-se que a violação ao direito das mulheres grávidas no momento do parto pode ser considerada como uma espécie de violência, pois perdem a autonomia sobre o seu corpo, e que a garantia do direito ao acompanhante pode diminuir a incidência desse tratamento. Conclusão: essa violência fica evidente em diversas ocasiões, como na atenção mecanizada e técnica por parte dos profissionais de saúde e, pela presente pesquisa, nota-se que, em parte, esse tratamento ocorre na ausência de acompanhamento da gestante por uma pessoa de sua confiança, razão pela qual é possível afirmar que o cumprimento efetivo de leis que protegem o direito do acompanhante pode reduzir significamente os casos de violência obstétrica.

\section{Palavras-chave}

Violência. Obstétrica. Saúde. Parto.

\begin{abstract}
Objective: to make a systematic review of studies on obstetric violence, reflecting on the parturient's right to the companion as a means of ensuring her physical and psychological health. Methods: bibliographic search of articles from different open access databases and indexers, published in full in Portuguese from August 2019 to July 2020. It was selected scientific journals in Health Law and Public Health with high impact factor. Data from official documents made available on the websites of the Brazilian Ministry of Health, the Perseu Abramo Foundation and the World Health Organization were also used. Results: it was found

\footnotetext{
${ }^{1}$ Mestranda em Direito e Instituições do Sistema de Justiça, Universidade Federal do Maranhão, São Luís, Maranhão, Brasil. https://orcid.org/0000-0002-1731-460X. E-mail: natalie_oam@hotmail.com

${ }^{2}$ O presente trabalho foi realizado com o apoio da Coordenação de Aperfeiçoamento de Pessoal de Nível Superior (Capes).

3 Pós-doutora em Direito Sanitário, Fundação Oswaldo Cruz, Brasília, Brasília, DF, Brasil; professora, Faculdade de Direito, Universidade Federal do Maranhão, São Luís, Maranhão, Brasil. https://orcid.org/0000-0001-6064-1879. E-mail: edithramosadv@yahoo.com.br
} 
that the violation of the right of pregnant women at the time of childbirth can be considered a violence, as they lose their autonomy over their body, and that guaranteeing the right to a companion can reduce the incidence of this treatment. Conclusion: this violence is evident on several occasions, among them in the mechanized and technical attention on behalf of health professionals and, in this research, it is noted that, in part, this treatment occurs in the absence of monitoring of the pregnant woman by a person of their confidence, which is why it is possible to affirm that the effective enforcement of laws that protect the companion's right can significantly reduce the cases of obstetric violence.

\section{Keywords}

Violence. Obstetric. Health. Childbirth.

\section{Resumen}

Objetivo: realizar una revisión sistemática de los estudios sobre la violencia obstétrica, reflexionando sobre el derecho de la parturienta al acompañante como medio para prevenir la seguridad de su salud física y psicológica. Metodología: levantamiento bibliográfico de artículos obtenidos de diferentes bases de datos e indexadores, publicados íntegramente en portugués y con acceso gratuito desde agosto de 2019 hasta julio de 2020. Se seleccionaron revistas científicas del área de Derecho Sanitario y Salud Pública, con extractos A y B en Qualis/Capes. También se utilizaron datos de documentos oficiales disponibles en los sitios web del Ministerio de Salud de Brasil, la Fundación Perseu Abramo y la Organización Mundial de la Salud. Resultados: se encontró que la violación del derecho de las mujeres embarazadas en el momento del parto puede ser considerado como una forma de violencia, ya que pierde la autonomía sobre su cuerpo, y que garantizar el derecho a un acompañante puede reducir la incidencia de este tratamiento. Conclusión: esta violencia se manifiesta en varias ocasiones, entre ellas en la atención mecanizada y técnica por parte de los profesionales de la salud y, en la presente investigación, se observa que, en parte, este tratamiento se da en ausencia de seguimiento de la gestante por parte de una persona de su confianza, por lo que es posible afirmar que la aplicación efectiva de las leyes que protegen el derecho del acompañante puede reducir significativamente los casos de violencia obstétrica.

\section{Palabras clave}

Violencia. Obstétrico. Salud. Parto.

\section{Introdução}

O parto é um fenômeno fisiológico que, não raro, está associado à ideia de violência contra a mulher, fazendo surgir, portanto, um novo termo: violência obstétrica. Enquanto o termo violência significa a imposição de um grau significativo de dor e sofrimento evitáveis, essa nova forma de violência, a obstétrica, foi caracterizada pela Organização Mundial de Saúde (OMS), em 2002, pela apropriação do corpo e dos processos reprodutivos da mulher pelos agentes de saúde, mediante tratamento desumanizado, abuso de medicalização e patologização dos processos naturais que resultam na perda de autonomia da paciente e de sua capacidade decidir de maneira livre e motivada sobre seu corpo e sexualidade (1). Tratase de uma violação aos direitos das mulheres grávidas em processo de parto que, entre outras consequências, resulta na perda da autonomia e decisão sobre o corpo pela própria 
parturiente. Estudos demonstraram que a equipe médica passou a encarar o parto simplesmente como um procedimento cirúrgico, dispendendo, nesses casos, apenas o tratamento técnico às pacientes, deixando de lado a importância da humanização nesses processos (2).

São diversas as leis com o objetivo de assistir a gestante em todas as suas fases, para garantir sua integridade física e mesmo sua dignidade humana. Não obstante essa busca pelos aparatos jurídicos, o que se percebe é a violação desses direitos, corroborando com o fenômeno da violência obstétrica. A efetivação da garantia do direito ao acompanhante visa a segurança da parturiente e o bem-estar de seu trabalho de parto e cujo descumprimento contra a vontade da gestante implica em violência obstétrica. Isso porque, conforme será explanado, a presença do acompanhante em todas as fases do parto garante à parturiente a sensação de segurança necessária para o bom andamento do processo do parto. O que se espera em relação ao direito ao acompanhante é que as parturientes tenham amplo conhecimento acerca da possibilidade de exigi-lo, considerando os impactos de seu descumprimento na saúde da gestante e do bebê.

Por meio das pesquisas utilizadas neste trabalho, se pretendeu demonstrar que a não punição para os casos de descumprimentos da lei do acompanhante e a falta de legislação existente acerca da violência obstétrica permitem que a mulher sofra mais experiências negativas, o que aumenta significativamente com a ausência de uma pessoa escolhida pela parturiente para presenciar os momentos que antecedem o parto, o próprio momento do parto, e o período que vem depois.

\section{Metodologia}

Foi feita uma revisão bibliográfica sobre a violência obstétrica e a importância da figura do acompanhante enquanto um instrumento auxiliador para a diminuição de maus tratos ou tratamento inadequado durante o período que antecede o parto, o momento do parto, e o período posterior ao parto, sendo considerado ainda que a sua ausência, quando contrária ao desejo das gestantes, enquadra-se como um dos tipos de violência obstétrica.

Para compreender o problema da pesquisa, foram apresentados conceitos acerca da violência e da obstetrícia, para chegar-se ao termo violência obstétrica; em seguida, demonstrou-se a importância da presença do acompanhante com base na proteção trazida por leis e normas; realizando-se, por fim, uma análise acerca de como a companhia de uma pessoa escolhida pela gestante poderia trazer menos danos à sua saúde e à saúde do bebê. 
Foi feito um levantamento bibliográfico de artigos obtidos em diferentes bancos de dados e indexadores, publicados na íntegra em português e acessados de forma gratuita no período de agosto de 2019 a julho de 2020. Foram selecionadas revistas científicas na área do Direito Sanitário e da Saúde Coletiva, com extratos A e B no Qualis/Capes. Utilizou-se, ainda, dados constantes em documentos oficiais disponibilizados nos sites do Ministério da Saúde brasileiro, da Fundação Perseu Abramo e da Organização Mundial de Saúde, tendo essa pesquisa se dado entre agosto de 2019 a julho de 2020, a partir dos descritores violência obstétrica; parto e violência contra a mulher; violência obstétrica e OMS nos sítios de busca.

Após o levantamento bibliográfico, fez-se a leitura exploratória e, em seguida, foram separados os artigos que definiram e analisaram o tema da violência obstétrica. Por fim, fezse uma leitura sistemática para a composição do material a partir de categorias de análises que dão nomes aos tópicos que compõem o trabalho.

\section{Resultados e discussões}

Apontamentos sobre a violência obstétrica

Considerada uma das formas de violência contra a mulher, são diversas as tentativas de definição acerca do que seria o fenômeno denominado violência obstétrica. Inicialmente, conforme a OMS (1), esse tipo de violência pode ser definido enquanto a imposição de um grau significativo de dor e sofrimento que podem ser evitados à gestante. Para a Convenção Interamericana para Prevenir, Punir e Erradicar a Violência contra a Mulher, de 1994, tratase de qualquer ato ou conduta baseada no gênero que possa resultar em morte, dano, sofrimento físico, social ou psicológico à mulher, seja na esfera de atendimento público ou privado (3). Também se inclui entre a violência obstétrica a violência por negligência, que ocorre por meio da negativa de atendimento ou das imposições de dificuldades para que as gestantes tenham seus direitos observados, incluindo o descumprimento do direito da mulher de ter um acompanhante (4).

A violência obstétrica se tornou mais perceptível em 2010 quando pesquisa realizada pela Fundação Perseu Abramo comprovou que 25\% das mulheres que tiveram partos normais sofreram de algum tipo de maus-tratos ou desrespeito em alguma das fases do parto (5), ou seja, uma a cada quatro mulheres sofreram alguma espécie de violência. Esse tipo de violência caracteriza-se pela apropriação do corpo e dos processos reprodutivos da mulher pelos agentes de saúde que lhe disferem tratamento desumanizado, com abuso de 
medicalização e patologização dos processos naturais, gerando perda da autonomia da parturiente e da sua capacidade de decidir sobre seu corpo e sexualidade (6). As mulheres são submetidas a procedimentos invasivos e violentos por acreditarem na necessidade da intervenção, além de confiarem na equipe médica responsável pelo seu parto. No entanto, parte desses procedimentos não possuem embasamento científico e violam os direitos sexuais e reprodutivos da mulher, além de expor a parturiente e até mesmo o bebê ao risco de incapacidade e/ou morte.

Conforme as Boas Práticas de Atenção ao Parto e ao Nascimento, publicação da OMS (1), de 2014, foram elencadas quatro categorias de práticas que são comuns na condução do parto, dependendo de sua utilidade, eficácia e grau de periculosidade:

- práticas demonstravelmente úteis que devem ser estimuladas: respeito à escolha da mãe sobre o local do parto; respeito ao direito da mulher à privacidade no local do parto; respeito à escolha da mulher sobre seus acompanhantes durante o trabalho de parto e parto; liberdade de posição e movimento durante o trabalho de parto; fornecimento às mulheres sobre todas as informações e explicações que desejarem;

- práticas claramente prejudiciais ou ineficazes e que devem ser eliminadas: uso rotineiro de enema; uso rotineiro de tricotomia; exame retal; revisão uterina rotineira após o parto; massagem e distensão do períneo durante o segundo estágio do trabalho de parto;

- práticas sem evidências suficientes e que devem ser usadas com cautela: clampeamento precoce do cordão umbilical; manipulação ativa do feto no momento do parto; pressão do fundo durante o trabalho do parto;

- práticas frequentemente usadas de modo inadequado: restrição hídrica e alimentar durante o trabalho do parto; monitoramento eletrônico fetal; uso de máscaras e aventais estéreis durante a assistência de parto.

Também se considera violência obstétrica os abusos verbais, procedimentos não permitidos, recusa em administrar analgésicos e a proibição da presença do acompanhante. Logo, percebe-se que essa violência possui diversas formas de penetrar no período do parto, desde maneiras sutis até as maneiras mais violentas.

A escolha das mulheres pela cesárea também está relacionada à violência, isso porque ela perde a autonomia nas decisões sobre o seu parto, ao se tornar um objeto de manipulações sem consentimento ou sem a informação suficiente sobre os processos a 
serem realizados (2). Por conta disso, há a dificuldade do reconhecimento da violência praticada, visto que muitas vezes as atitudes podem ser percebidas como atos técnicos derivados dos profissionais da saúde, profissionais técnicos-administrativos de instituições públicas e privadas, ou qualquer outra pessoa que se utilize da condição gravídica para realizar os atos acima descritos. A dificuldade na constatação ocorre tanto com a vítima quanto com seus acompanhantes, visto que na maioria dos casos não possuem capacidade técnica para aferir ou contestar sua incidência, principalmente pelo estado de vulnerabilidade da vítima que busca resguardar a sua vida e a de seu filho (7). A violência obstétrica é complexa porque se estabelece em três tipos de relações: a violência no âmbito individual, institucional e estrutural (8).

Resta claro que esse fenômeno tem sido percebido na medida em que o parto deixou de ser compreendido enquanto um fenômeno natural e familiar, passando a ser visto como um procedimento cirúrgico comum próprio do ambiente hospitalar e, portanto, institucionalizado:

[o] evento complexo do parto e nascimento se tornou, ao longo dos últimos séculos, um assunto médico e hospitalar, separado da vida familiar e comunitária [...] O parto medicalizado e hospitalar tornou-se sinônimo de modernidade, de segurança e de ausência de dor. $E$, mais contemporaneamente, de espetáculo (9).

A violência institucionalizada verificada na prestação dos serviços de saúde caracteriza-se pela negligência e maus-tratos dos profissionais com os usuários - as parturientes -, incluindo a violação dos direitos reprodutivos e a peregrinação por diversos serviços até que a mulher receba o atendimento necessário, além da aceleração do parto com fins de desocupar os leitos (2). Tal violência pode ser explicada por um conjunto complexo de circunstâncias, no qual:

[...] os partos complicados e as parteiras (bem como os médicos) despreparadas ceifaram muitas vidas; a criação de maternidades separadas de hospitais gerais e a adoção de medidas de higiene e isolamento reduziram as mortes maternas hospitalares; a evolução da técnica da cesariana a tornou segura para salvar a vida de mães e bebês, no caso de partos com complicações; e os médicos se empenharam em divulgar tanto sua técnica e perícia quanto uma postura humanitária e filantrópica (9).

O procedimento do parto passou a ter como regra o risco de patologias e complicações, justificando a necessidade das intervenções médicas e inaugurando um modelo tecnocrático de assistência ao parto (9). Assim, o principal objeto do obstetra passa 
a ser o útero e o seu produto, em vez da mulher. Como consequência dessa percepção do corpo da mulher enquanto máquina, tem-se, inicialmente, a eliminação da concepção da mulher enquanto sujeito do parto, substituindo-a pelo médico, de modo que passa a caber a ele a condução do parto. Em seguida, há o impedimento de que os médicos reconheçam como legítimas as situações em que o ambiente externo e o estado emocional da mulher dificultam ou facilitam o procedimento do parto. Por fim, define e determina as intervenções do médico quando ele achar que o músculo uterino não está respondendo apropriadamente. Por essas práticas e rotinas se tornarem padrão, Maia ressalta que:

[a] imagem fragmentada do corpo máquina e da mulher útero, associada com a ideia do hospital como uma linha de produção, permitiu que se instituísse uma assistência padronizada que inclui a prática de deslocar a mulher durante o trabalho de parto (9).

Percebe-se ter havido a institucionalização do parto, que permitiu a implementação de um cenário em que há uma relação de poder e hierarquia entre o médico e a parturiente (10).

Essas ações intervencionistas e, muitas vezes, desnecessárias, têm ocasionado a insatisfação das mulheres, que são relegadas a coadjuvantes nos processos de parto e nascimento. O parto passa a integrar um modelo centralizado na figura do médico e que exclui outros profissionais da saúde, como enfermeiras, que por formação estariam habilitadas para atender o parto normal (2).

Também é preocupante o fato de que essa violência seja silenciosa: em algumas situações a parturiente não se dá conta da violência praticada contra ela ou prefere não contar que a sofreu por medo de sofrer abandono por parte do profissional em um momento de alta vulnerabilidade ou por não se sentir apoiada para oferecer a denúncia do tratamento inadequado e agressivo (6). Logo:

Dentro dos serviços de saúde, usuárias e profissionais não associam os maus-tratos na assistência ao parto como formas de violência. Segundo pesquisa realizada por Aguiar (2010), as gestantes e os profissionais de saúde consideram esses acontecimentos como prática rotineira ou como resposta ao esgotamento das equipes frente a mulheres queixosas (2).

Predomina a ideia de que a violência está mais relacionada com uma agressão física ou sexual, não sendo compreendida, portanto, entre as práticas diárias ou experiências vividas na sala de parto (2). Com base no exposto, tem-se uma quebra na relação de confiança entre mulheres e profissionais de saúde, fragilizando os vínculos existentes. Isso 
porque a mulher se sujeita a concordar com as vontades impostas pelos profissionais, tornando-se, portanto, subordinada e refém a esse saber-poder por eles imposto. Assim, é possível dizer que o medo e a insegurança existentes nos processos obstétricos alimentam a violência presente no procedimento (11).

Esse quadro exige uma mudança no cenário da obstetrícia, considerando que o parto, antes de ser uma situação cirúrgica, trata-se primeiro de um momento de grande significado na vida da mulher. $\mathrm{O}$ tratamento mais humano no momento do atendimento e a promoção da assistência no sentido de reduzir os impactos negativos gerados a partir de uma possível violência devem ser garantidos. É nesse contexto, de promoção do bem-estar da mulher no momento do parto que deve ser assegurado o seu direito ao acompanhante.

\section{O direito da parturiente ao acompanhante}

Uma das tantas formas de violência obstétrica é a proibição do acompanhante, recomendada pela OMS desde 1985 na Conferência sobre Tecnologia Apropriada Para Nascimento e Parto (7). Não obstante, o que se percebe é uma prática institucionalizada nos hospitais, no sentido de não permitir a entrada do acompanhante ou não garantindo esse direito de maneira plena, respeitando aquilo que assegura a lei. Como resultado disso, temse uma interferência na vida privada, planejamento familiar e no amparo psicológico da parturiente (7).

A institucionalização da violação obstétrica normaliza o descumprimento desse direito e corrobora a sua reprodução. Assim, é possível "[...] facilmente reproduzi-la de modo a concebê-la inconsciente e rotineiramente sem questionamento de sua eventual necessidade [...]" (7). Como um instrumento de garantia desse direito, inicialmente foi editada a Lei no 8.080 de 1990 que, entre outras providências, dispõe sobre as condições para a promoção proteção e recuperação da saúde, organização e o funcionamento dos serviços correspondentes. Posteriormente, essa lei foi alterada pela Lei no $11.108 / 2005$, que trouxe como garantia o direito da parturiente à presença do acompanhante durante o trabalho de parto, parto e pós-parto imediato, no âmbito do Sistema Único de Saúde (SUS), seja de rede própria ou conveniada (12).

Para garantir o cumprimento dessa lei e expandir o conhecimento para as partes interessadas acerca do presente direito, o art. 19-J, incluído pela Lei oㅡ 11.108/2005, em seu $\S 3^{\circ}$, obriga os hospitais de todo o País a manter, em local visível de suas dependências, aviso informando sobre o direito da parturiente ao acompanhante (12). Além de garantir às 
parturientes 0 direito ao acompanhante, a lei sujeita o hospital a deixar essa informação visível caso alguma paciente o desconheça. A lei destaca que o acompanhante deve ser indicado pela própria parturiente (art. 19-J, $\S 1^{\circ}$ ), pois reconhece a possibilidade, ainda que remota, de que a equipe médica possa subtrair esse direito de escolha. Essa proteção se dá ainda pela Resolução da Diretoria Colegiada (RDC) no 36/2008, da Agência Nacional de Vigilância Sanitária (13), e pela Resolução Normativa (RN) oㅡ 262/2011, da Agência Nacional de Saúde (14). A RDC no 36/2008 afirma que a presença do acompanhante é de "livre escolha da mulher" e que deve ser garantida sua privacidade e de seu acompanhante, além de garantir a este último "atendimento humanizado" e "poltrona removível" (13). De igual modo, a RN o 262/2001, ao dispor sobre o rol de procedimentos e eventos em saúde, garante a cobertura de despesas relativas à paramentação, alimentação e acomodação dos acompanhantes "indicados pela mulher" (14).

Visando proteger também a parturiente e criança, o Estatuto da Criança e do

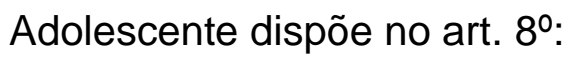

É assegurado a todas as mulheres o acesso aos programas e às políticas de saúde da mulher e de planejamento reprodutivo e, às gestantes, nutrição adequada, atenção humanizada à gravidez, ao parto e ao puerpério e atendimento pré-natal, perinatal e pós-natal integral no âmbito do Sistema Único de Saúde. $\S 60$ A gestante e a parturiente têm direito a 1 (um) acompanhante de sua preferência durante o período do pré-natal, do trabalho de parto e do pós-parto imediato (15).

Além disso, o Estatuto prevê no art. 8ํ, § 6ํㅜ, que, em caso de adolescentes grávidas, a gestante e a parturiente têm direito a um acompanhante de sua preferência durante 0 período do pré-natal, do trabalho de parto e do pós-parto imediato (15).

Conforme se percebe, a lei tem buscado a proteção da integridade física e psicológica da mulher de várias maneiras, protegendo a parturiente e o bebê em todas as fases do parto. $O$ fato de o acompanhante estar integrando um dos direitos garantidos no momento do parto e de forma tão reiterada reforça a ideia da importância do acompanhante para a parturiente. No entanto, o que se tem percebido por meio dos relatos das pesquisas demonstradas por Diniz et al (16) é que esse direito de mulheres grávidas ou parturientes serem acompanhadas antes, durante e depois do parto, é descumprido frequentemente, reforçando a violência contra a mulher, especificamente no que diz respeito a violência obstétrica. Um dos motivos pelo qual isso ocorre é pelo desconhecimento do direito pelo sujeito que deveria exercê-lo. É necessário que as mulheres sejam informadas, nos períodos pré-parto, durante o parto e 
pós-parto, sobre o seu direito ao acompanhante no decorrer de toda a internação até o final do parto, incluindo a recuperação cirúrgica ou anestésica. Essa garantia se estende também nos casos de aborto e demais complicações, a exemplo da gestação ectópica e molar (16). Portanto, para que esse direito seja cobrado e exercido, é necessária a divulgação da informação com antecedência e clareza que possibilite à mulher e à família fazer os arranjos que forem precisos para garantir a escolha e participação do acompanhante (16).

É importante investir na disseminação da informação por meio de campanhas que visem conscientizar acerca dos direitos das gestantes, assim como é necessária uma urgente edição na lei do acompanhante de modo a prever pena pelo descumprimento dos hospitais em divulgarem o direito ao acompanhante por meio de placas nas paredes conforme exigido pela lei. A prática de ambas essas medidas pode tornar o direito mais exigível ao ficar mais conhecido e ao fazer com que as instituições saibam que o descumprimento tem condão punitivo.

\section{O acompanhante como instrumento de proteção}

São cada vez mais frequentes o descaso e o desrespeito com as gestantes na assistência ao parto, seja no setor público ou no setor privado de saúde. Casos vem à tona seja por meio da imprensa ou da força atual das redes sociais, quando mulheres relatam experiências traumáticas sofridas num momento natural da vida, que por vezes acaba sendo visto como uma experiência puramente cirúrgica (2).

Entre fevereiro de 2011 e outubro de 2012, a Fundação Oswaldo Cruz realizou a primeira pesquisa a oferecer um panorama nacional sobre a situação da atenção ao parto e nascimento no Brasil intitulada Nascer no Brasil: Inquérito Nacional sobre Parto e Nascimento. Envolveu um grande número de pesquisadores renomados e teve como objetivo conhecer os determinantes, a magnitude e os efeitos das intervenções obstétricas no parto, incluindo os casos de cesarianas que se deram desnecessariamente, as intervenções médicas durante o puerpério e o período neonatal, além de descrever a estrutura das instituições hospitalares quanto à qualificação dos recursos humanos, disponibilidade de insumos, equipamentos, medicamentos e unidade de terapia intensiva (UTI) para adultos e neonatos (17).

A pesquisa foi realizada em maternidades públicas, privadas, e privadas conveniadas ao SUS, incluindo 266 hospitais de médio e grande porte, localizados em 191 municípios, incluindo capitais e cidades do interior de todos os estados do Brasil. Foram 90 puérperas 
em cada hospital, com permanência mínima de sete dias em cada um deles, viabilizando entrevistas em mulheres que pariram durante o dia ou durante à noite, tanto em feriados quanto em finais de semana (17).

O resultado foi que, mesmo quase uma década depois da promulgação da lei do acompanhante, menos de $20 \%$ das mulheres se beneficiavam da presença contínua do acompanhante durante todo o período de internação, e a maioria das mulheres que contaram com a presença do acompanhante consideraram o fator "útil ou muito útil" para ter uma experiência melhor e mais calma no parto ( $91,2 \%$ das respostas válidas) (17). Mesmo com o posterior aumento desse índice, verificado na pesquisa, ainda há muito o que se fazer em prol da garantia desse direito.

A revisão sistemática mais recente acerca do tema, citada na pesquisa de Diniz et al (16), mostra que com o apoio contínuo no parto, as mulheres eram mais propensas a ter parto vaginal espontâneo e menos propensas a utilizar analgesia intraparto ou relatar insatisfação; o trabalho de parto era mais curto, e se davam menos por meio de cesariana ou parto vagina instrumental. As mulheres que tinham acompanhantes relataram mais satisfação com o atendimento e afirmam terem recebido mais informações, o que fez com que se sentissem mais respeitadas pelos profissionais. Por meio das análises de subgrupos, foi possível perceber que esse apoio contínuo foi mais eficaz quando advindo de alguém que não fazia parte da equipe do hospital ou da rede social da mulher e que houve menor incidência de qualquer forma de violência durante a internação. Ou seja, a presença de acompanhante pode ser compreendida enquanto um indicador de segurança, de qualidade do atendimento e de respeito pelos direitos das mulheres na assistência (16).

Percebe-se, a existência de um conflito de interesses na organização da assistência ao parto (16). Isso porque há uma resistência à garantia do acompanhante para a mulheres que influencia na promoção de um ambiente de nascimento saudável, levando-as a optarem pelas cesáreas com a intenção de se sentirem mais protegidas da violência institucional presente no momento do parto. Conforme a OMS, a opção da mulher ao acompanhante durante todo o período do parto trata-se de uma das práticas demonstrada útil que deve ser estimulada, considerando ser protetora das formas de violência durante o tempo necessário para internação hospitalar, além de promover maior satisfação materna com o processo de parto; encorajamento das mulheres; entre outros benefícios (1). O apoio contínuo "[...] otimiza a fisiologia do parto e os sentimentos de controle e competência das mulheres, reduzindo a dependência de intervenções médicas [...]" (6). 
Conforme demonstra Serra (6) em pesquisa realizada por meio de revisão sistemática da literatura, na qual analisou 41 artigos sobre o suporte oferecido à mulher durante 0 processo de parto no período de 10 anos, a presença do acompanhante minora o sofrimento, ansiedade e medo da mulher. Assim, torna o processo de parturição mais natural e menos traumático (6). É importante que a paciente tenha suporte emocional atrelado aos sentimentos de segurança e confiança, levando à diminuição do nível de estresse materno e depressão pós-parto (6). Deve-se considerar que, durante todo o processo de parto, a mulher está recebendo diversos estímulos com sensações diferentes, de modo que toda atitude que puder colaborar para um procedimento mais tranquilo, seguro e saudável deve ser adotada.

São poucas as experiências humanas comparáveis com o parto e o nascimento, considerando a intensidade física, psicológica e social, pois se trata de um evento histórico e socialmente construído, com ampla variabilidade cultural e geográfica. Além disso, o cuidado que a parturiente recebe durante o parto, assim como a qualidade da experiência para ela, são marcadores da posição que ela e o bebê ocupam nessas hierarquias sociais, incluindo dimensões como classe social, raça/etnia, estado de saúde, estado civil, capacidade física, respeitabilidade sexual e outros (16). Daí a importância da humanização no tratamento, visto que colabora com a reafirmação do lugar de protagonista da mulher no momento do parto.

Não obstante as exigências da lei e a comprovação do benefício trazido pela presença do acompanhante, as leis não são cumpridas e muitas mulheres continuam tendo seu direito violado. Durante a negativa do acompanhamento, os argumentos que justificam a negação do acompanhante fundam-se nas necessidades institucionais baseadas na estrutura física dos hospitais ou ainda profissionais, quando a decisão passa a ser um critério do médico (2). Resultados da pesquisa de Diniz et al (16) demonstram que, entre as mulheres que não tiveram acompanhante durante o parto, $52 \%$ dos casos se deu pelo não cumprimento institucional da legislação, principalmente sob o argumento de que não se permitia nenhum tipo de acompanhante no hospital, além de outras formas de restrições: "[...] somente para cesarianas ou para adolescentes, para acompanhantes mulheres, para aqueles que participaram de um curso, para aqueles que tivessem pago etc." (16).

Percebe-se, a necessidade de alteração em todo o contexto de aplicação da lei, para que ela seja cumprida de maneira eficaz e traga, de fato, o benefício que dela se espera para as parturientes. Também é preciso a elaboração de novas normas, pois nota-se a falta 
de leis pontuais que tratem da proteção e garantia dos direitos necessários às mulheres, especificamente no período de suas gestações (4).

\section{Conclusão}

O período da gravidez é repleto de dificuldades naturais do próprio procedimento em questão. No entanto, há casos em que se imputa à mulher sofrimento desnecessário ou que poderia ser evitado, seja para facilitar o trabalho da equipe médica ou pelo simples fato de que uma escolha nesse momento não foi tomada pela própria paciente. Percebe-se a vulnerabilidade da mulher nesse momento, na medida em que desconhece a razão de algumas intervenções ou não escolhe se submeter a elas.

Em ambos os casos, ocorre o fenômeno denominado violência obstétrica, que pode ser conceituado como um tipo de violência específica contra a mulher em que há a imposição de dor e sofrimento evitáveis (1). Além dessa imposição de violência, percebe-se também a apropriação dos processos reprodutivos das mulheres, que se dá, entre outros fatores, por meio da atenção mecanizada e da atribuição de medicamentos excessivos à mulher.

Outro modo de cometer a violência contra a mulher é privá-la do seu direito ao acompanhante assegurado por lei, pois a observância desse direito pode diminuir os demais casos de violência obstétrica. Isso porque a presença do acompanhante pode inibir o comportamento de médicos, enfermeiras e de toda a equipe médica, garantindo à paciente um parto debaixo de sua autonomia e seu consentimento.

Ocorre que, embora haja instrumentos jurídicos garantindo o direito ao acompanhante, ele não é assegurado e reproduzido pelas instituições responsáveis pelo parto. Os hospitais afirmam, diversas vezes, que não possuem condições estruturais de acomodar o acompanhante do paciente, ou que não há obrigatoriedade no cumprimento dessa lei uma vez que ela não possui sanção prevista em caso de descumprimento.

Além disso, o apoio institucional é determinante e essencial para a produção de mudanças nas equipes de saúde, modificando as relações e corresponsabilizando os profissionais com o intuito de aperfeiçoamento das práticas de cuidado e atenção impostas às gestantes. Logo, com o auxílio e interesse da equipe médica responsável pelo parto, é possível alcançar uma mudança significativa no contexto da violência obstétrica.

É necessário buscar alteração na lei com a finalidade de reforçar sua obrigatoriedade, principalmente por meio de sanção em caso de descumprimento. A importância do acompanhante para a parturiente é clara a tal ponto que mesmo diversas leis buscam sua 
garantia. Ademais, robustecer a ideia de que a parturiente tem esse direito por meio da divulgação dessa informação também é um mecanismo importante para a garantia desse direito na medida em que ele será mais exigido.

Deve-se buscar assegurar os direitos fundamentais da assistência obstétrica e buscar a desmedicalização do nascimento, uma prática profissional pautada na medicina de evidência, buscando, além do direito ao acompanhante, o consentimento livre e esclarecido da gestante antes, durante e depois do procedimento do parto. É fundamental, portanto, trazer visibilidade para essa questão, por meio de campanhas, criação de canais de denúncia e ações de conscientização voltadas para população em geral. Dessa maneira, espera-se que o desrespeito a esse processo natural cesse, permitindo à mulher autonomia total sobre o seu corpo e sobre todas as fases do seu parto, garantindo a sua segurança, a segurança do bebê e uma experiência livre de traumas e outras consequências negativas.

\section{Referências}

1. Organização Mundial de Saúde. Assistência ao parto normal: um guia prático. Genebra: OMS; 2002.

2. Zanardo GLP, Calderón UM, Nadal AHR, Habignang LF. Violência obstétrica no Brasil: uma revisão narrativa [Internet]. Porto Alegre: PUC/RS; 2017 [acesso em 13.set.2019]. Disponível em: http://www.scielo.br/pdf/psoc/v29/1807-0310-psoc-29-e155043.pdf

3. Organização dos Estados Americanos. Convenção para prevenir, punir e erradicar a violência contra a mulher (Convenção de Belém do Pará) [Internet]. Adotada em 9 de junho de 1994 [acesso em 12.set.2019]. Disponível em: http://www.cidh.oas.org

4. Hamermüller A, Uchôa T. Violência obstétrica atinge 1 em cada 4 gestantes no Brasil, diz pesquisa [Internet]. Humanista: Jornalismo e Direitos Humanos. 2018 [acesso em 12.set.2018]. Disponível em: https://www.ufrgs.br/humanista/2018/01/28/violenciaobstetrica-atinge-1-em-cada-4-gestantes-no-brasil-diz-pesquisa/

5. Venturi G, Godinho T. Mulheres brasileiras e gênero nos espaços público e privado [Internet]. São Paulo: Sesc/Fundação Perseu Abramo; 2010 [acesso em 12.set.2019]. Disponível em: http://csbh.fpabramo.org.br/sites/default/files/pesquisaintegra.pdf

6. Serra MCM. Violência obstétrica em (des)foco: uma avaliação da atuação do Judiciário sob a ótica do TJMA, STF e STJ. [Dissertação]. São Luís: Universidade Federal do Maranhão; 2018. 227 fls.

7. Oliveira LGSM, Albuquerque A. Violência obstétrica e direitos humanos dos pacientes. Revista CEJ [Internet]. 2018 [acesso em 17.set.2019]; 22(75):36-50. Disponível em: http://www.mpsp.mp.br/portal/page/portal/documentacao_e_divulgacao/doc_biblioteca/bibli _servicos_produtos/bibli_boletim/bibli_bol_2006/Rev-CEJ_ñ.75.03.pdf 
8. Oliveira AL. Violência obstétrica: uma análise de suas dimensões nas normativas Brasileiras [Monografia na internet]. Brasília: Unb; 2016 [acesso em 17.set. 2019]. 69 fls. Disponível em: http://bdm.unb.br/bitstream/10483/15883/1/2016_AmandaLimadeOliveira_tcc.pdf

9. Maia MB. Assistência à saúde e ao parto no Brasil. In: Maia MB. Humanização do parto: política pública, comportamento organizacional e ethos profissional [Internet]. Rio de Janeiro: Fiocruz; 2010 [acesso em 17.set]. Disponível em:

http://books.scielo.org/id/pr84k.2019]. p. 19-49. ISBN 978-85-7541-328-9.

10. Cunha E. Violência no parto em Minas Gerais [Internet]. Denúncia à Comissão de Direitos humanos da Assembleia Legislativa. Belo Horizonte; 2012 [acesso em 2.set.2019]. Disponível em:

http://www.redehumanizasus.net/sites/default/files/violencia_no_parto_em_minas_gerais__versao_final.pdf

11. Jardim DMB, Modena CM. A violência obstétrica no cotidiano assistencial e suas características. Rev. Latino-Am [Internet]. Enfermagem. 2018 [acesso em 30.set. 2019];26:e3069. Disponível em: http://www.revistas.usp.br/rlae/article/view/156599/152086

12. Brasil. Lei $n^{0} 11.108$, de 7 de abril de 2005. Altera a Lei no 8.080 , de 19 de setembro de 1990, para garantir às parturientes o direito à presença de acompanhante durante o trabalho de parto, parto e pós-parto imediato, no âmbito do Sistema Único de Saúde SUS. Brasília, 7 abr 2005 [acesso em 10.set.2019]. Disponível em: http://www.planalto.gov.br/ccivil_03/_ato2004-2006/2005/lei/l11108.htm

13. Brasil. Agência Nacional de Vigilância Sanitária. Resolução no 36, de 3 de junho de 2008. Dispõe sobre Regulamento Técnico para Funcionamento dos Serviços de Atenção Obstétrica e Neonatal. Brasília: Anvisa; 2008.

14. Brasil. Agência Nacional de Saúde Suplementar. Resolução Normativa $n^{\circ}$ 262, de 1 de agosto de 2011. Atualiza o Rol de Procedimentos e Eventos em Saúde previstos na RN no 211, de 11 de janeiro de 2010. Brasília: ANS; 2011.

15. Brasil. Lei no 13.257, de 8 de março de 2016. Dispõe sobre as políticas públicas para a primeira infância e altera a Lei no 8.069, de 13 de julho de 1990 (Estatuto da Criança e do Adolescente) [...]. Brasília, 8 mar 2016 [acesso em 12.set.2019]. Disponível em: http://www.planalto.gov.br/ccivil_03/_Ato2015-2018/2016/Lei/L13257.htm\#art18

16. Diniz CSG et al. Implementação da presença de acompanhantes durante a internação para o parto: dados da pesquisa nacional Nascer no Brasil. Cad. Saúde Pública [Internet]. 2014 [acesso em 2.set.2019];30(Supl.):S140-S153. Disponível em: https://doi.org/10.1590/0102-311X00127013.

17. Leal MC et al. Nascer no Brasil: Inquérito Nacional sobre Parto e Nascimento [Internet]. Rio de Janeiro: ENSP/Fiocruz; 2012 [Acesso em 5.set.2019]. Disponível em: http://www.ensp.fiocruz.br/portal-ensp/informe/site/arquivos/anexos/nascerweb.pdf 


\section{Colaboradores}

Almeida NMO contribuiu com a redação; análise e interpretação de dados; e redação final do artigo. RAMOS EBM contribuiu para a concepção/desenho do artigo; revisão crítica e aprovação da versão final.

\section{Como citar este artigo:}

Almeida NMO, Ramos EMB. O direito da parturiente ao acompanhante como instrumento de prevenção à violência obstétrica. Cadernos Ibero-Americanos de Direito Sanitário. 2020 out./dez.; 9(4): 12-27.

https://doi.org/10.17566/ciads.v9i4.643 